Journal of Engineering and Applied Sciences 15 (3): 752-761, 2020

ISSN: 1816-949X

(C) Medwell Journals, 2020

\title{
Evaluation of Computational Fluid Dynamic Model in Investigating the Hydraulic Performance of Stepped Spillway
}

\author{
Uday A.M. Alturfi, Hayder Mohammed Jasim AL-Moadhen and Hayder Sami Mohammed \\ Faculty of Engineering, University of Kufa, Najaf, Iraq
}

\begin{abstract}
Computational Fluid Dynamics (CFD) modelling in field of hydraulic structures and river engineering is continuously growing in recent years, through applied this powerful tool for modeling several types of multiphase flow. The objective of current study, it is to extends clear understanding of multiphase flow around stepped spillway for different steps configuration and to test the capabilities of the CFD Model (Fluent 18.2) to represent these phenomena. VOF method adopted to capture interface between water and air, k- $\varepsilon$ turbulent model for turbulence parameters and (PISO) Pressure Implicit with Splitting of Operator algorithm is used. Experimental study is carried out for four model configuration according to the steps aspect ratio $\mathrm{H}_{s} / \mathrm{L}_{\mathrm{s}}$ $(1,0.75,0.6$ and 0.5$)$ for flow rate range $\left(10,15\right.$ and $\left.20 \mathrm{~L} \mathrm{sec}^{-1}\right)$. physical model made from plywood with smooth surface. CFD Model demonstrated an acceptably recorded result in predicting the energy dissipation rate for different steps configuration compering with the experimental results. Also, it is obtained that the energy dissipation rate is increases with increase the steps aspect ratio. time steps size it about 0.005 sec or less are recommend to capture the flow pattern and secondary flow around stepped spillway.
\end{abstract}

Key words: CFD, VOF Model, multiphase flow, stepped spillway, turbulence k-e, physical modeling, energy dissipation rate, turbulence kinematic energy

\section{INTRODUCTION}

In recent years, new hazard classification for existing reservoirs have been changed because boundary conditions have been developed. Consequently, many of these dams no longer provide adequate spillway capacity according to state and federal dam safety regulations. Stepped spillways are a most powerfully choice for provide a means to increase flowrate capacity without necessarily causing other modifications to the dam dimensions. The stepped spillway, one of the most important types of spillway used to reduce the size and depth of the energy dissipation tank at the toe of the dam. This type of spillway works to dissipate the energy through the movement of water over the aging of the steppes, resulting in water vortices during the transition from the upstream of the spillway to downstream.

Stepped spillway strategy is not new. In fact, specified the innovation back to $1300 \mathrm{BC}$ design rules are as yet restricted, even more, so for the flatter sloped (2(H):1(V) or flatter) stepped spillways associated with small existing dams. Therefore, used new analysis approaches (CFD) to study the effect of steps aspect ratio (high/length) resulting in the amount of energy dissipation is one of the interested of several researchers.

Al-Shukur, et al. (2014) studied an examination in view of research approaches analyses expects to explore the stream attributes and vitality dispersal rates on six unique arrangements of steps of stepped spillway which are: (sloped and end sills which were settled on the downstream of the level face of all means) (Al-Shukur et al., 2014).

In the research of Zhan et al. (2016), three modeling strategy by computational fluid dynamic had been adopted, volume of fluid, Eulerian and mixture method are used to simulate the water-air entrainment. This approaches are coupled with Navier-equation with LES (large eddy simulations) as turbulent model discretization, (Zhan et al., 2016).

Al-Hashimi et al. (2017) aimed to investigate a compression of CFD modeling by FLUENT solver with experimental study of flow over wire. Four turbulent model are utilize in this study, standard k-epsilon, k-omega, RAG k-epsilon and realizable k-epsilon to. The results shows that the flow and free surface profile are turbulent and so, difficult to predicts (Al-Hashimi et al., 2017).

Felder and Chanson (2013) adopted some of permeable pooled stepped spillways were investigated with two different porosities of the pooled weir. The air-water stream entrainment, air-water stream properties and the vitality scattering rate were watched and compared with the relating non-pooled and pooled stepped spill-ways (Felder and Chanson, 2013).

Maatooq and Ojaimi (2014) adopted new composite spillway name as stepped labyrinth spillway. The basic 
concept of this study by use the specification of a labyrinth weir as a stepped spillway to make new hydraulic structures with modified notifications. Results of this study shows that the new spillway had more efficient in case of dissipation of energy (Maatooq and Ojaimi, 2014). Nikseresht et al. (2013) examined the two-stage stream more than two kinds of step-pool spillway was researched utilizing two-stage plans Volume of Fluid (VOF) and mature model and different turbulence demonstrating. Numerical reproduction of two-eliminate stream was carried on two kinds of step-pool spillway with different slants (Nikseresht et al., 2013).

Daneshfaraz et al. (2014) adopted a comparison of two discretization strategies in the numerical displaying of the free surface stream over stepped and ogee spillways has been introduced. FLUENT solver has been utilized for the numerical arrangement by means of Finite Volume Method (FVM) and for the Finite Element Method (FEM) ADINA has been utilized as a part of writing (Daneshfaraz et al., 2014).

Dabling and Crookston (2012) studied the flow characteristics of multiple staged and notched labyrinth weir configurations were tested. Water depth-discharge relationships were computed experimentally and compared with received results using superposition (predicting the flow rate over the upper and lower stages separately and summing) (Dabling and Crookston, 2012)

\section{MATERIALS AND METHODS}

Computational Fluid Dynamic (CFD) Model: CFD is a numerical engineering technical which is used to predict fluid flow in many field of physics. Multiphase flow one of the most powerful solver available by CFD. ANSYS V.18.2 and provided many solvers for wide range physics engineering, one of the most important solver in field of fluid flow and heat transfer for multiphase flow is FLUENT V.18.2.

This study represents a 2D modeling a flow by using FLUENT 18.2 solver to predicted the hydraulic performance over stepped spillway for multiphase flow. VOF method adopted to capture interface between water and air and the other solver setting are described prefill in the Table 1.

Three basic stages must be passed when modeling using CFD methodology: problem identification (geometry, domain discretization, mesh size, mesh type), pre-processing (boundary conditions, solver setting, time step size and other solver setting) and post-processing (result and conclusion compression). Figure 1, each of these steps must be full identified details.

Mesh discretization (mesh independent solution): It is more comfortable to utilize fine meshes for fluid flow calculations in order to cover any primary and secondary

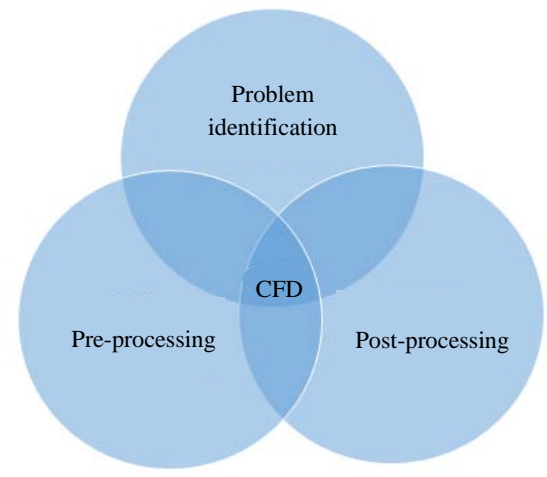

Fig. 1: Main stages for any CFD calculation

Table 1: Solver setting for CFD Model (ANSYS .18.2. FLUENT)

Solution method Pressure-velocity coupling

Discretization scheme SIMPLE algorithm

Momentum

Pressure

Volume fraction

Turbulent kinetic energy

Turbulent dissipation rate

Transient formulation

Viscous Model

Near wall treatment

Time step size

$\underline{\text { Residual for all equation parameters }}$

Second order upwind PISO

Comprehensive

Second order upwind Second order upwind First order implicit $\mathrm{k}-\varepsilon$ Model standers Scalable wall function $0.0005 \mathrm{sec}$ 0.00001

details of flow, for example, eddies, secondary flow and velocity shears. Meshes were created based on various criteria (Najmeddin, 2012).

First, grid size should be fine enough in order to capture rapid variations in the velocity distributions, especially, grid near wall boundaries. This recommendation is satisfied by performing refine mesh or creates inflation layer near to solid walls where eddies and secondary flow are expected to appear, Fig. 2.

Second, to minimize error in CFD the computational results should be not affect structure of meshes (structures, unstructured mesh) used for flow computations. In other words, the outcome computational results produced should be independent of the meshes configurations in the model. In order to satisfy these recommendation, several mesh size are adopted to produce the progressive fine mesh. The strategies used $\left(1 \times 10^{-3}, 3 \times 10^{-3}\right.$ and $\left.7 \times 10^{-3} \mathrm{~m}\right)$ mesh size to carry out model runs mesh that have independent computational results. Minimal error received for grid size $1 \times 10^{-3} \mathrm{~m}$.

Third, the total account of grid nodes shouldn't be excessively larger, resulting in increases the computation time. The larger number of grid nodes will also create more complex in the post processing of model output (Najmeddin, 2012). The strategy procedures in all models set a minimum of $10^{5}$ iterations and a maximum of $15 \times 10^{4}$ iterations with a convergence criterion for most effect parameters set to $10^{-5}$, Fig. 3 residuals with iteration per time steps. 


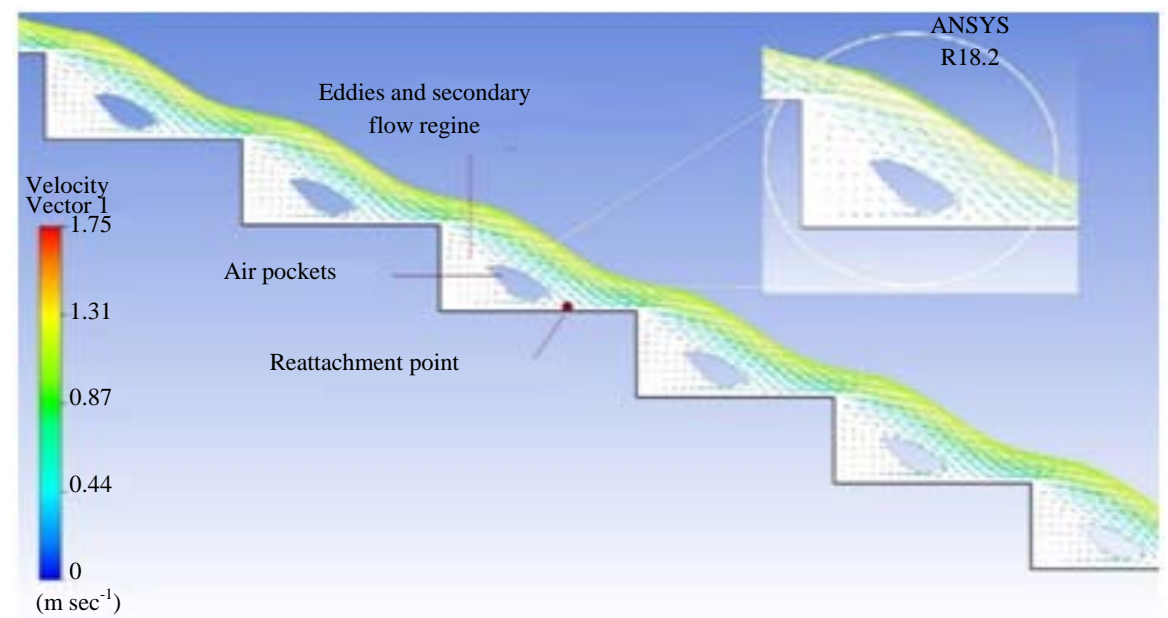

Fig. 2: Eddies and air pockets colored by velocity vectors

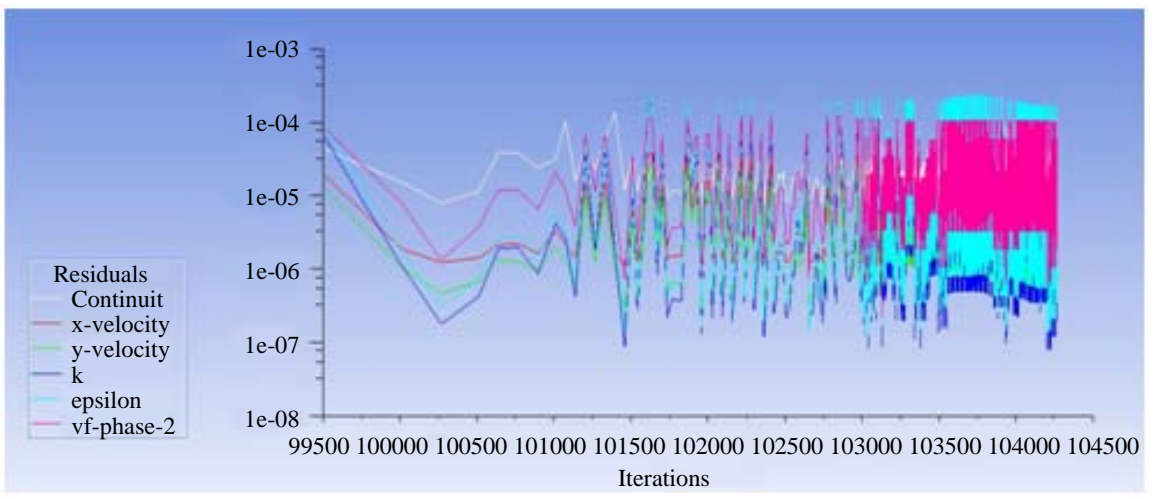

Fig. 3: Residuals-iteration per time steps for model

Boundary conditions and domain discretization: Modeling methodology in CFD required to fully define the fluid flow domain (Najmeddin, 2012). The alternative use of boundary conditions in CFD modeling are: inlet (velocity inlet, mass flow inlet, pressure inlet), outlet (velocity outlet, pressure outlet, mass flow outlet), sidewalls (no-slip conditions, slip conditions). Figure 4 shows the appropriate use boundary conditions in the present study.

Experimental set-up: Experimental study was conducted by hydraulics laboratory of Kufa University-Faculty of Engineering-Iraq (open channel tailing water), Fig. 5. Experimental works were produced in $15 \mathrm{~m}$ flume long, smooth glass-walled having a section of $0.3 \mathrm{~m}$ width by $0.45 \mathrm{~m}$ depth. A storage tank, of $45000 \mathrm{~L}$ capacity is located at the downstream end of the flume. Water is transport from the upstream tank to an outlet tank of $500 \mathrm{~L}$ capacity at the upstream end by means of a pump having most extreme release of $40 \mathrm{~L} \mathrm{sec}^{-1}$.
Model description: In laboratory work four wooden models were used, Fig. 6a-c. Each model has a specific aspect ratio (Hs/Ls) 1, 0.75, 0.6, 0.5. Flow rate discharge is measured by means of a pre-calibrated sharp-crested rectangular weir. Three values of flow rate are measured, (10, 15 and $\left.20 \mathrm{~L} \mathrm{sec}^{-1}\right)$ with free surface depth above the bed not less than $3 \mathrm{~cm}$ in the upstream side.

Equation 1 present the pre-calibrated equation (measured the time required to full the continuer with known volume) to measure the flow rate passing through the flume (Khassaf and Al-Baghdadi, 2015).

$$
\mathrm{Q}=0.596(\mathrm{~h})^{1.5694}
$$

Where:

$\mathrm{Q}$ : Flow rate of flume $\left(\mathrm{L} \mathrm{sec}^{-1}\right)$

$\mathrm{h}$ : Head (depth of water) (cm)

Principle of specific energy equation: The concept of specific energy equation is very important when study of 


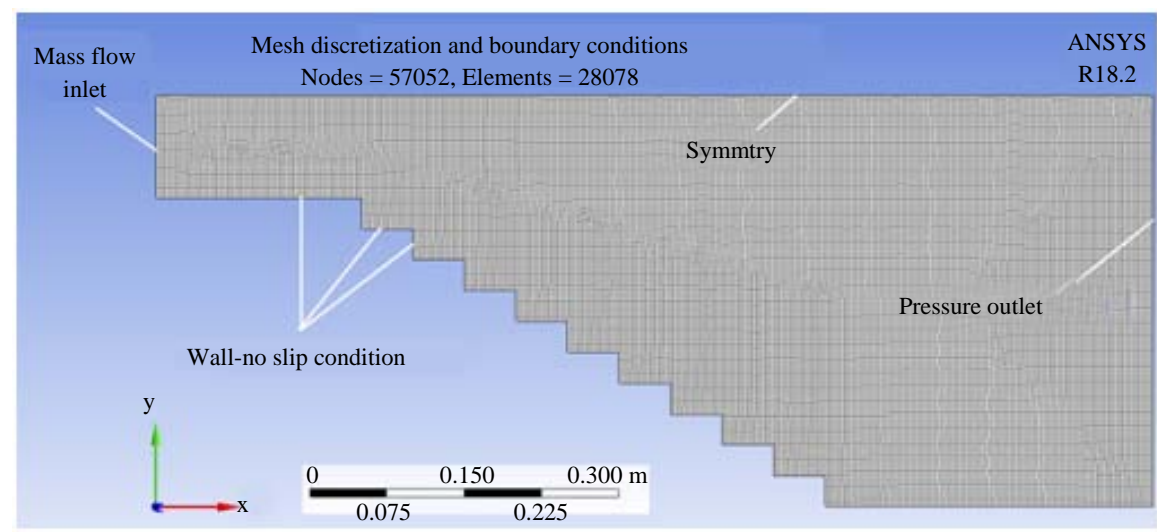

Fig. 4: Boundary conditions and domain discretization

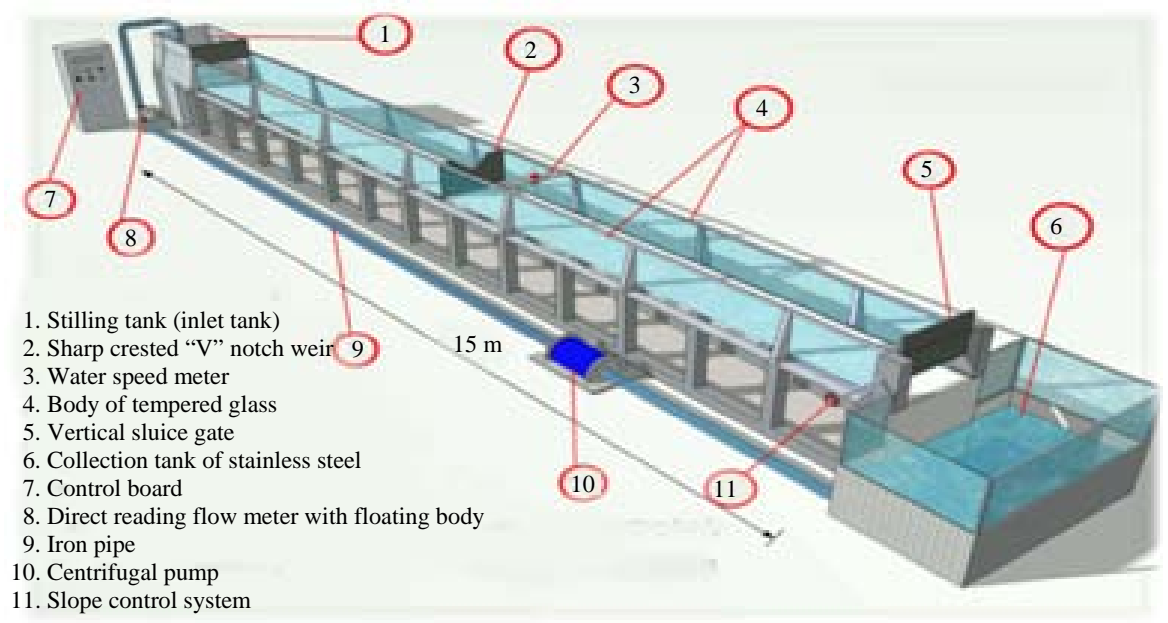

Fig. 5: Sketch of flume description (Aziz and Nasret, 2014)

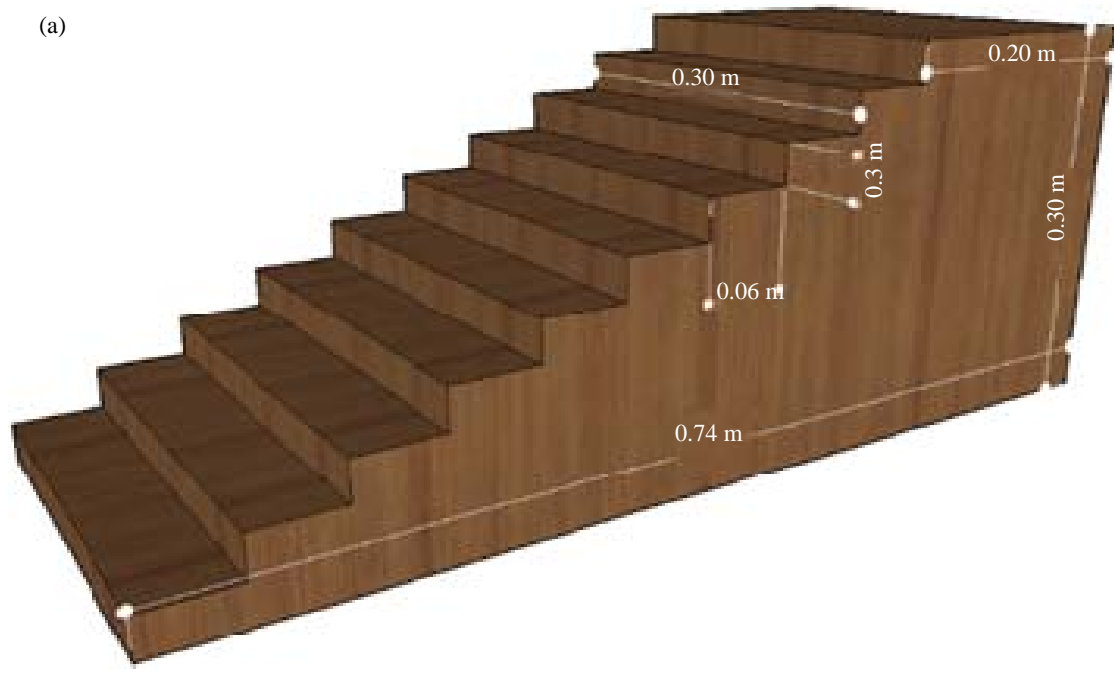

Fig. 6(a-c): Continue 

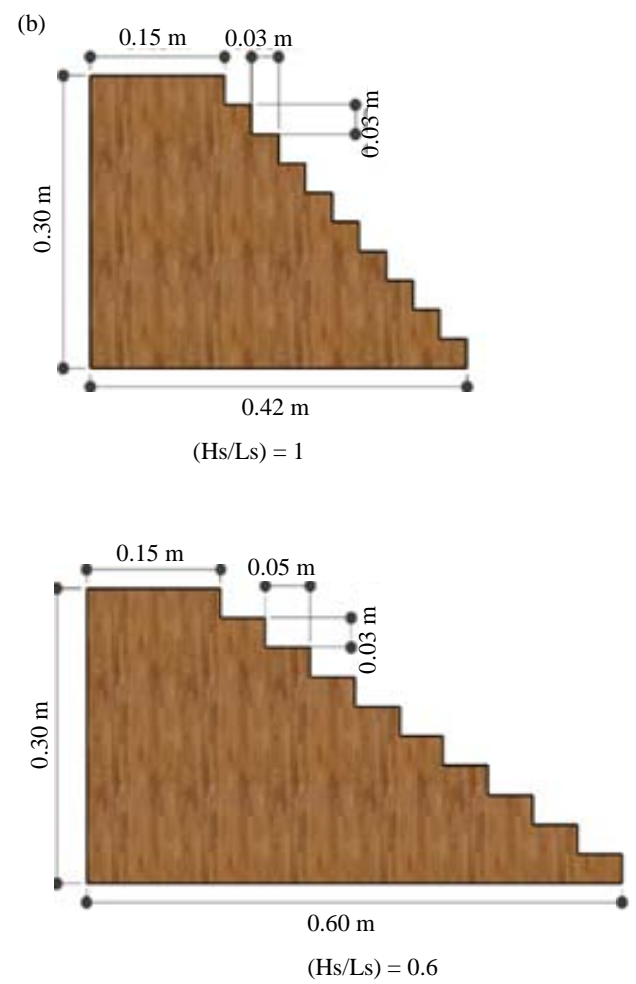
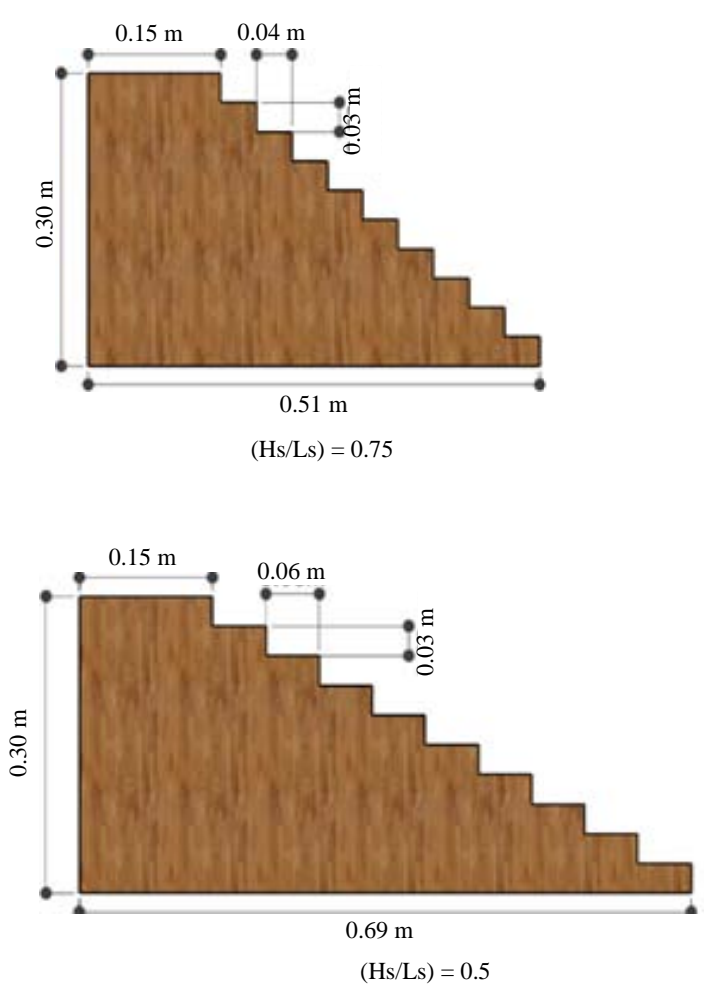

(c)

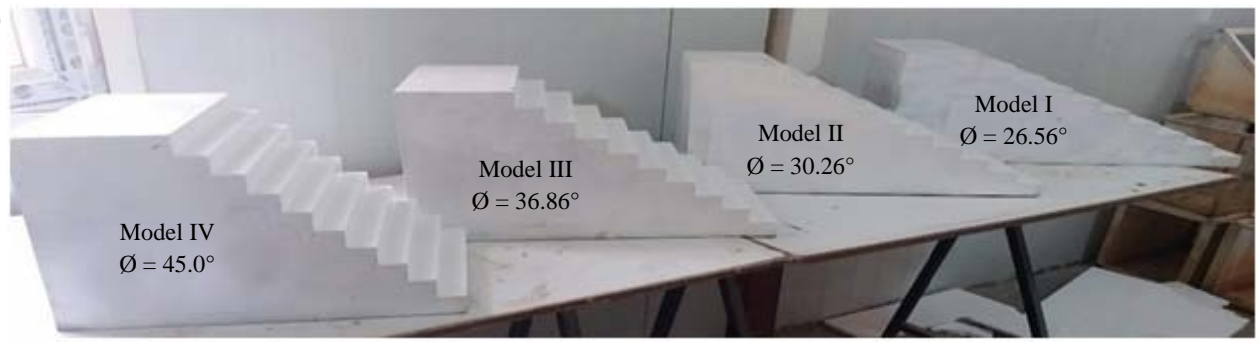

Fig. 6(a-c): Models descriptions (a) Sketch 3D Model of stepped spillway with dimension $\left(\mathrm{H}_{\mathrm{S}} / \mathrm{L}_{\mathrm{s}}=0.5\right)$, (b) Sketch 2D Model of stepped spillway with dimension for all senior and (c) View of wooden model for all steps configurations

free surface flow in open-channel. Using the channel bed as references, the specific energy, $\mathrm{E}$ is defined as Najmeddin (2012):

$$
\mathrm{E}=\mathrm{y}+\mathrm{v}^{2} / 2 \mathrm{~g}
$$

Where:

$$
\begin{array}{lll}
\mathrm{E} & : & \text { Specific energy } \\
\mathrm{V} & : & \text { Velocity } \\
\mathrm{g} & : & \text { Acceleration }
\end{array}
$$

In case of rectangular channel section, the specific energy equation re-written as:

$$
\mathrm{E}=\mathrm{y}+\mathrm{q}^{2} / 2 \mathrm{gy}^{2}
$$

Where:

b : Width of the channel

$\mathrm{q}$ : Flow rate per unit width

In order to calculated the energy loss produced by using the stepped spillway, initial specific energy $\left(E_{0}\right)$ in upstream side and final specific energy $\left(E_{1}\right)$ in downstream side are measured, Fig. 7. Difference in between two energy measured (upstream and downstream) represent energy loss. The energy loss in the steps including the energy loss due to friction and the energy loss due to flow separation and eddy motions. Equation 4 and 5 present specific energy in upstream and downstream, respectively. 
J. Eng. Applied Sci., 15 (3): 752-761, 2020

Table 2: CFD and experimental date for specific energy and loss predicted for various steps configuration

\begin{tabular}{|c|c|c|c|c|c|c|c|c|c|}
\hline \multirow{2}{*}{$\begin{array}{l}\text { Steps configuration } \\
\text { aspect ratio (Hs/Ls) }\end{array}$} & \multirow{2}{*}{$\begin{array}{l}\text { Flow rate } \\
\left(\mathrm{L} \mathrm{sec}^{-1}\right)\end{array}$} & \multicolumn{4}{|l|}{ CFD } & \multicolumn{4}{|c|}{ Experimental } \\
\hline & & $\mathrm{E}_{0}$ & $E_{1}$ & $\Delta \mathrm{E}$ & $\Delta \mathrm{E}(\%)$ & $\mathrm{E}_{0}$ & $E_{1}$ & $\Delta \mathrm{E}$ & $\Delta \mathrm{E}(\%)$ \\
\hline \multirow[t]{3}{*}{0.5} & 10 & 0.3327 & 0.0522 & 0.280 & 84.28 & 0.33 & 0.059 & 0.271 & 82.10 \\
\hline & 15 & 0.3350 & 0.0814 & 0.254 & 75.73 & 0.34 & 0.088 & 0.244 & 74.11 \\
\hline & 20 & 0.3400 & 0.1230 & 0.225 & 64.63 & 0.35 & 0.144 & 0.205 & 58.80 \\
\hline \multirow[t]{3}{*}{0.6} & 10 & 0.3300 & 0.0560 & 0.276 & 83.16 & 0.33 & 0.060 & 0.270 & 81.81 \\
\hline & 15 & 0.3400 & 0.0830 & 0.257 & 75.50 & 0.34 & 0.091 & 0.249 & 73.23 \\
\hline & 20 & 0.3500 & 0.1370 & 0.213 & 60.76 & 0.35 & 0.141 & 0.209 & 59.71 \\
\hline \multirow[t]{3}{*}{0.75} & 10 & 0.3300 & 0.0599 & 0.271 & 81.93 & 0.33 & 0.065 & 0.265 & 80.30 \\
\hline & 15 & 0.3400 & 0.0866 & 0.254 & 74.59 & 0.34 & 0.090 & 0.250 & 73.50 \\
\hline & 20 & 0.3500 & 0.1456 & 0.205 & 58.57 & 0.35 & 0.165 & 0.185 & 52.85 \\
\hline \multirow[t]{3}{*}{1} & 10 & 0.3310 & 0.0649 & 0.267 & 80.62 & 0.33 & 0.072 & 0.258 & 78.18 \\
\hline & 15 & 0.3410 & 0.0940 & 0.246 & 72.16 & 0.34 & 0.110 & 0.230 & 67.60 \\
\hline & 20 & 0.3510 & 0.1560 & 0.194 & 55.38 & 0.35 & 0.166 & 0.184 & 52.57 \\
\hline
\end{tabular}

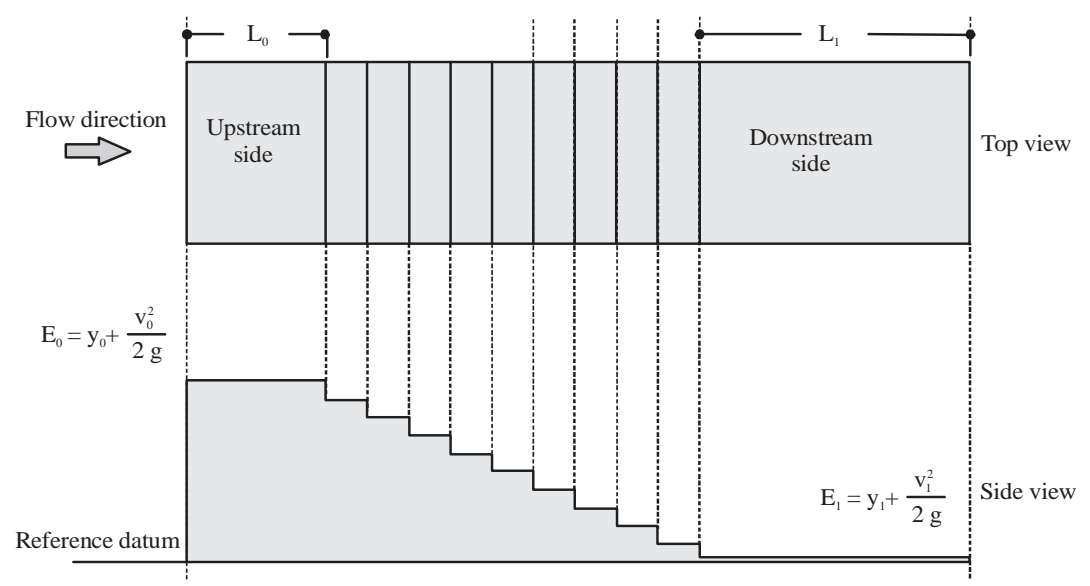

Fig. 7: Plan view of stepped spillway (side and top)

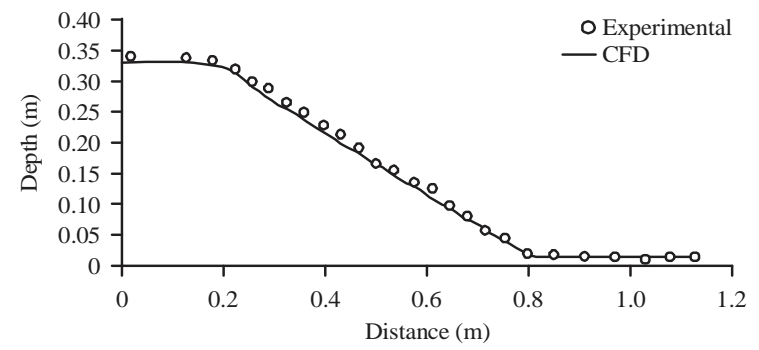

Fig. 8: Free surface profile for CFD and experimental data $\left(\mathrm{Q}=20 \mathrm{~L} \mathrm{sec}^{-1}\right.$ aspect ratio 0.5$)$

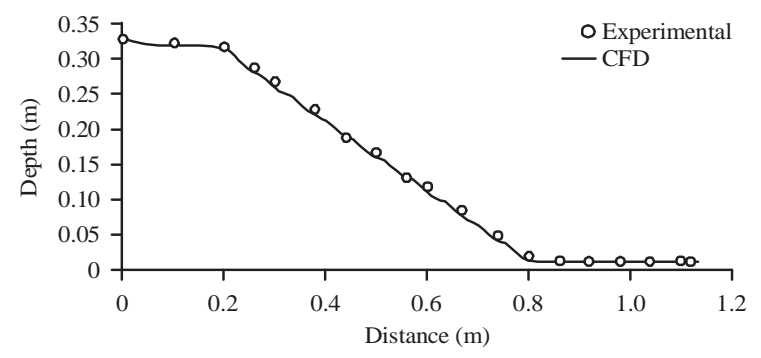

Fig. 9: Free surface profile for CFD and experimental data $\left(\mathrm{Q}=10 \mathrm{~L} \mathrm{sec}^{-1}\right.$ aspect ratio 0.5$)$

$$
\begin{gathered}
\mathrm{E}_{0}=\mathrm{y}_{0}+\mathrm{v}^{2} / 2 \mathrm{~g} \text { or: } \mathrm{E} 0=1.5 \mathrm{y}_{\mathrm{c}} \\
\mathrm{E}_{1}=\mathrm{y}_{1}+\mathrm{v}^{2} / 2 \mathrm{~g} \\
\Delta \mathrm{E}=\mathrm{E}_{0}-\mathrm{E} \\
\Delta \mathrm{E} \%=\mathrm{E} / \mathrm{E}_{0}
\end{gathered}
$$

Table 2 represent CFD and experimental date for specific energy and loss predicted for various steps configuration.

It can be seen that, the energy dissipations rate are increases with decreases the flow rate and increases with decreases of aspect ratio. When the high of steps are fixed, the decrease of aspect ratio lead to increases the length of steps that makes a significant time to dissipate the energy through the developed the eddies and air pocket in steps. The following figures present same of comparison between experimental observed data and CFD result, Fig. 8 and 9.

Figure 10, shows CFD results of the free surface flow over stepped spillway for various flow rate $(10,15$ 


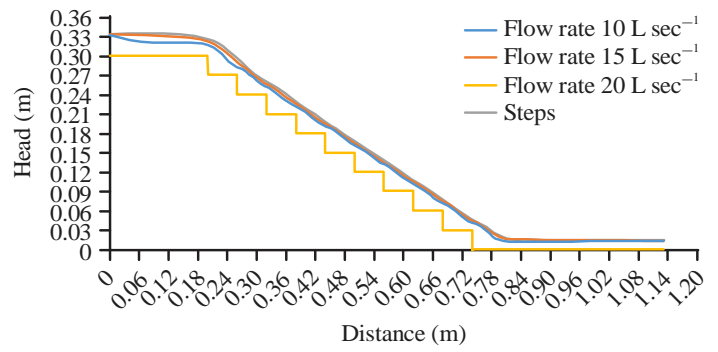

Fig. 10: CFD free surface profile for different flow rate for steps aspect ratio 0.5

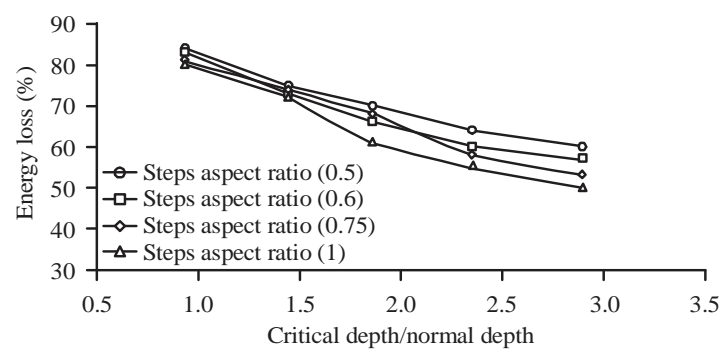

Fig. 11: CFD results of relations between energy loss according to the steps aspect ratio and $20 \mathrm{~L} \mathrm{sec}{ }^{-1}$ ) for steps aspect ratio 0.5. Figure 11, shows CFD results of the relations between energy loss and critical depth for different steps aspect ratio.

\section{RESULTS AND DISCUSSION}

CFD post-processing: In this part of study, some of graphical results of CFD analysis are presented for several variables that have obvious effect on the energy dissipations for stepped spillway. VOF (Volume of Fluid) on of the most important technics used in CFD calculation to predicted the free surface water or (separated line between two phase with different properties). Figure 12 shows the VOF of free surface flow with different aspect ratio $(1,0.75,0.6,0.5)$ for flow rate $\left(20 \mathrm{~L} \mathrm{sec}^{-1}\right)$.

Figure 13 and 14 show the flow vectors (streamline) colored by velocity for different aspect ratio. Figure 15 shows the flow vectors (streamline) colored by velocity for steps $(10,9,8,7)$. Figure 16 shows eddy viscosity concertation for different cases.
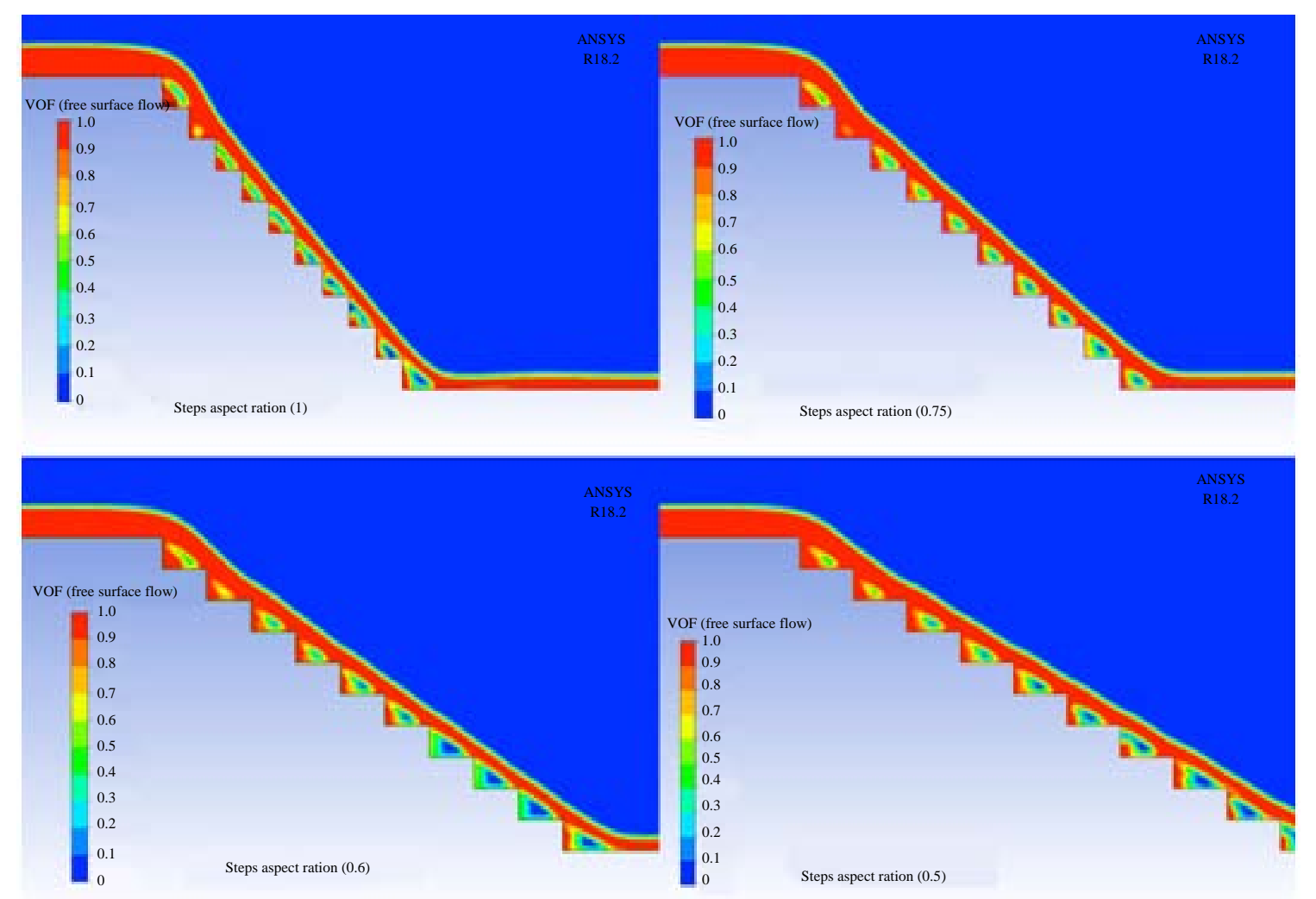

Fig. 12: The VOF of free surface flow with different aspect ratio 
J. Eng. Applied Sci., 15 (3): 752-761, 2020

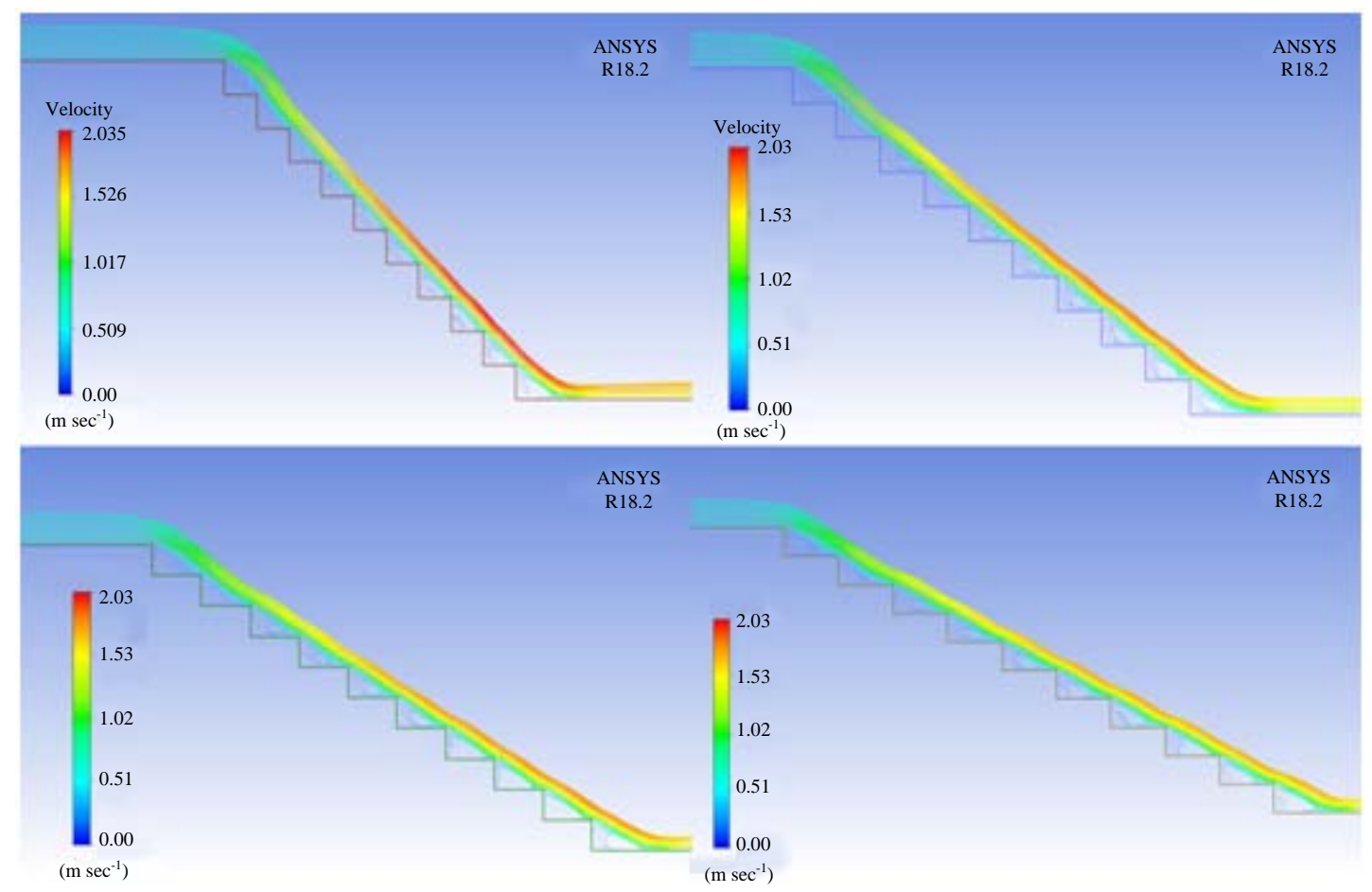

Fig. 13: Flow vectors (streamline) colored by velocity for different aspect ratio

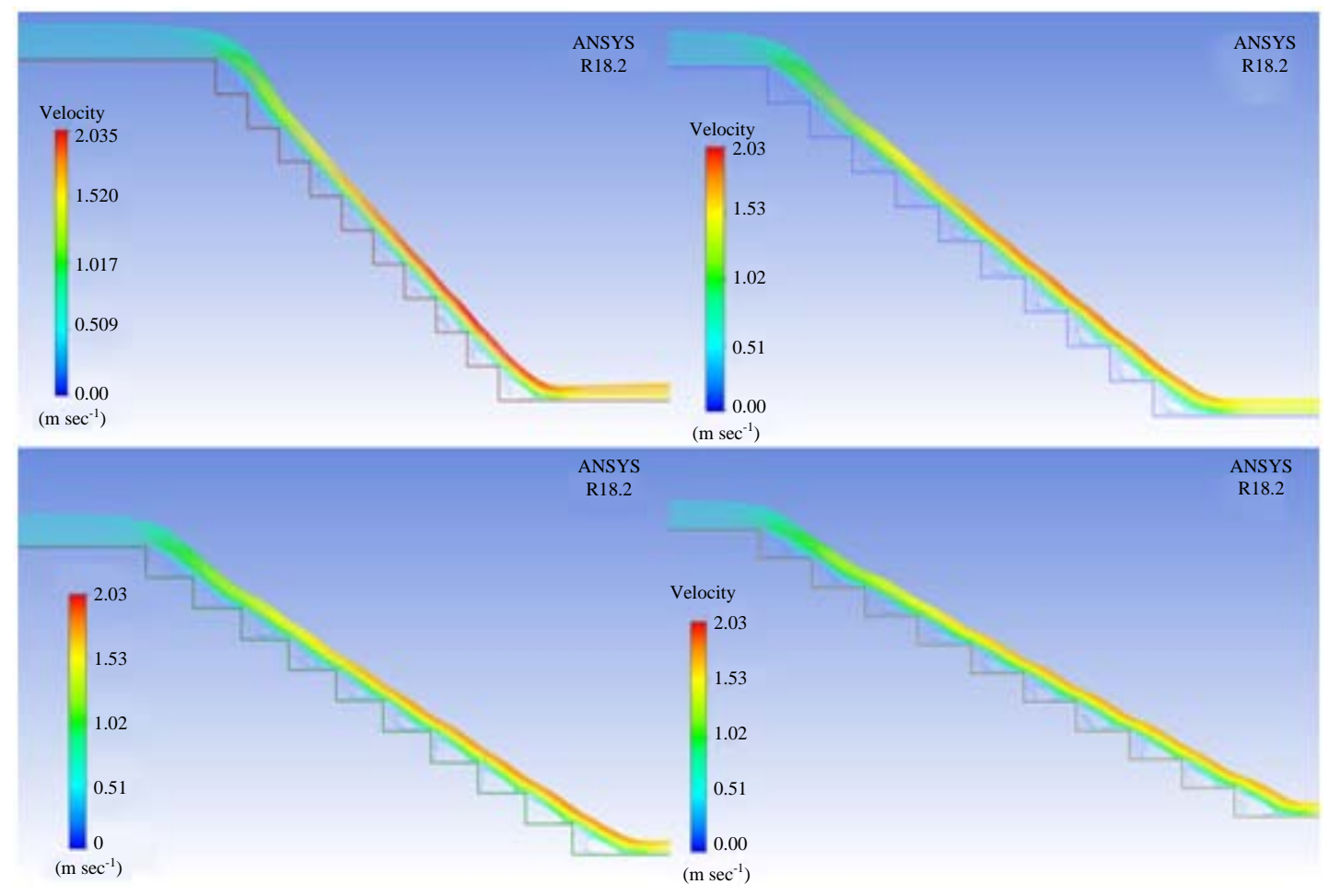

Fig. 14: Flow vectors (streamline) colored by velocity for different aspect ratio 


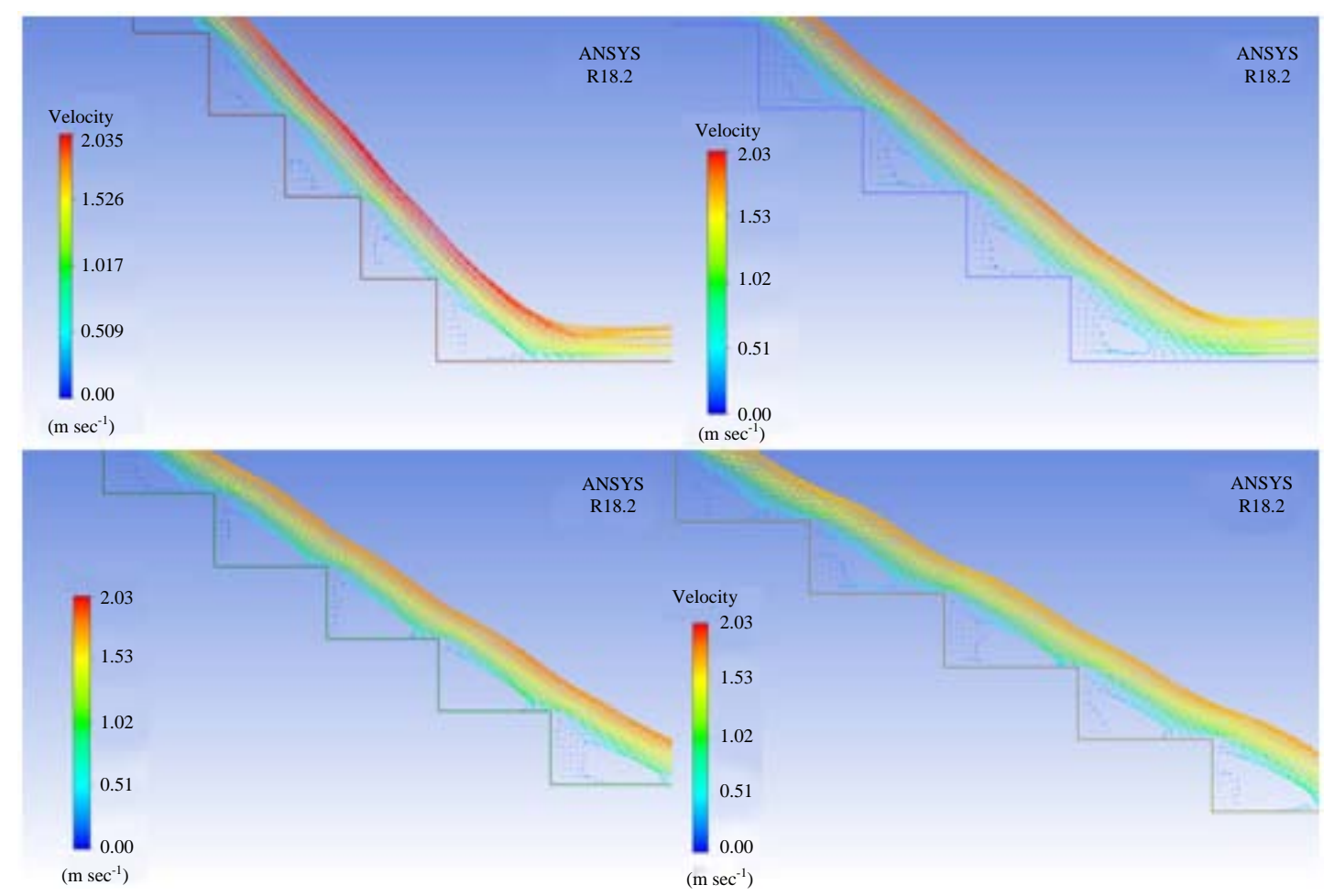

Fig. 15: Flow vectors (streamline) colored by velocity for steps $(10,9,8,7)$
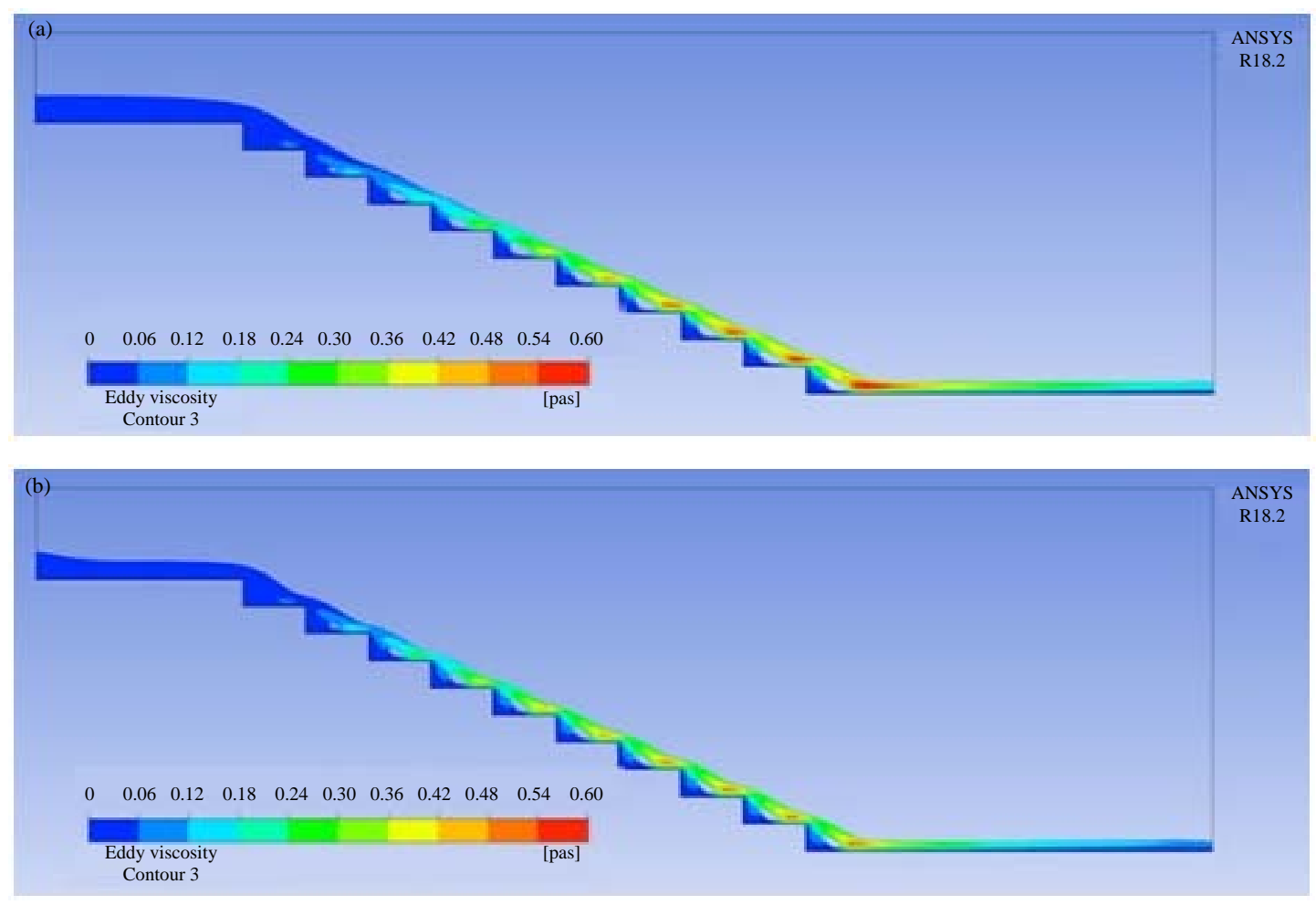

Fig. 16 (a-b): Eddy viscosity concertation for different flow rate (a) $20 \mathrm{~L} \mathrm{sec}^{-1}$ and (b) $10 \mathrm{~L} \mathrm{sec}^{-1}$ 


\section{CONCLUSION}

According to the experimental result compering with CFD results, the Computational Fluid Dynamic Model demonstrates good performance when applied to predicted the flow around stepped spillway. Mesh discretization and time steps size play as corner stone in the CFD Model, time step size was 0.005 and mesh size $0.001 \mathrm{~m}$. Overalls mass imbalance (flow rate in-flow rate out) to make the results more accurate it was about 0.01 . Also, $\mathrm{k}-\varepsilon$ model standers shows good predicted the recirculation flow around steppes.

In terms of the free surface flow and energy dispassion over stepped spillway, CFD Model provided a good agreement with experimental results for all model with error not exceeded 7\%. The result of CFD Model shows that; the energy dissipation rate of stepped spillway is increases with decrease the flow rate and decreases with decrees the aspect ratio of steps.

\section{REFERENCES}

Al-Hashimi, S.A.M., H.M. Madhloom and T.N. Nahi, 2017. Experimental and numerical simulation of flow over broad crested weir and stepped weir using different turbulence models. J. Eng. Sustainable Dev., 21: 28-45.

Al-Shukur, A.H.K., S.K.H. Al-Khalaf and I.M.A. Al-Sharifi, 2014. Flow characteristics and energy dissipation losses in different configurations of steps of stepped spillway. Int. J. Innovative Res. Sci. Eng. Technol., 3: 8823-8832.

Aziz, L.J. and M.T. Nasret, 2014. Investigat hydraulic performance of groins by computational fluid dynamic model. Intl. J. Sci. Eng. Res., 5: 143-153.
Dabling, M.R. and B.M. Crookston, 2012. Staged and notched labyrinth weir hydraulics. Proceedings of the 4th International Junior Researcher and Engineer Workshop on Hydraulic Structures (IJREWHS'12), June 17-20, 2012, Utah State University, Logan, Utah, pp: 28-35.

Daneshfaraz, R., B. Kaya, S. Sadeghfam and H. Sadeghi, 2014. Simulation of flow over ogee and stepped spillways and comparison of finite element volume and finite element methods. J. Water Resour. Hydraul. Eng., 3: 37-47.

Felder, S. and H. Chanson, 2013. Air entrainment and energy dissipation on porous pooled stepped spillways. Proceedings of the IWLHS 2013 International Workshop on Hydraulic Design of Low-Head Structures, February 20-22, 2013, BAW-Bundesanstalt fur Wasserbau, Karlsruhe, Germany, pp: 87-97.

Khassaf, S.I. and M.B. Al-Baghdadi, 2015. Experimental study of non-rectangular piano key weir discharge coefficient. Int. J. Energy Environ., 6: 425-436.

Maatooq, J.S. and T.Y. Ojaimi, 2014. Evaluation the hydraulic aspects of stepped labyrinth spillway. Eng. Technol. J., 32: 2174-2185.

Najmeddin, S., 2012. CFD modelling of turbulent flow in open-channel expansions. M.Sc. Thesis, Concordia University, Montreal, Canada.

Nikseresht, A.H., N. Talebbeydokhti and M.J. Rezaei, 2013. Numerical simulation of two-phase flow on step-pool spillways. Scientia Iranica, 20: 222-230.

Zhan, J., J. Zhang and Y. Gong, 2016. Numerical investigation of air-entrainment in skimming flow over stepped spillways. Theor. Applied Mech. Lett., 6: 139-142. 